\title{
Effects of seven silvicultural treatments on terrestrial salamanders
}

\author{
Douglas N. Harpole*, Carola A. Haas \\ Department of Fisheries and Wildlife Sciences, Virginia Polytechnic Institute and State University, Blacksburg, VA 24061-0321, USA
}

\begin{abstract}
We compared the relative abundance of terrestrial salamanders before and after application of seven regeneration treatments in a low-elevation, southern Appalachian hardwood forest in southwest Virginia. Treatments included understory removal, group selection, two shelterwoods, leave-tree, clearcut, and a control. Salamander relative abundance was significantly lower after harvest on the group selection ( $p=0.005$ ), shelterwoods $(p=0.007$ and $p=0.015)$, leave-tree $(p=0.001)$, and clearcut treatments $(p=0.001)$. There was no significant difference in relative abundance during the same period on the control $(p=0.788)$ or understory removal $(p=0.862)$ treatments. (C) 1999 Elsevier Science B.V. All rights reserved.
\end{abstract}

Keywords: Amphibian; Appalachians; Area-constrained search; Coverboard; Forest management; Salamander; Silviculture

\section{Introduction}

Salamanders are an important ecological component of Appalachian deciduous forests and can occur in densities such that the total salamander biomass in a given area can exceed that of other small vertebrate species (Burton and Likens, 1975; Hairston, 1987). Terrestrial salamanders feed on prey that are too small for birds or mammals and serve as prey for snakes, birds, small mammals, and other salamanders (Brodie and Howard, 1973; Brodie et al., 1979; Pough, 1980). Terrestrial salamanders forage in the forest floor litter primarily at night, after rainfall or during periods of high humidity. Species distributions vary according to moisture and elevation gradients throughout the southern Appalachians (Hairston, 1987).

Previous studies have shown that salamander populations decline after clearcut timber harvesting (Ash,

\footnotetext{
*Corresponding author. Tel.: +1-540-231-5703; e-mail: dharpole@vt.edu
}

1988; Pough et al., 1987; Petranka et al., 1993, Petranka et al., 1994). Clearcutting increases the surface temperature and leads to drying of the litter layer (Johnson et al., 1985) limiting salamander surface activity (Fraser, 1976; Jaeger, 1980). Although the effects of clearcut timber harvesting on terrestrial salamander populations have been documented, few studies have compared the effects of other silvicultural practices on terrestrial salamander populations in eastern deciduous forests of the United States (but see preliminary work by Bennett et al., 1980; Pough et al., 1987).

We compared the effects of seven different silvicultural treatments on relative abundance of terrestrial salamanders. Results are from 1 year preharvest, and 3 years of postharvest sampling at one study site.

\section{Materials and methods}

The study site is located in the Blacksburg Ranger District of the George Washington and Jefferson 
National Forest in southwest Virginia (Montgomery County, $37^{\circ} 17^{\prime} \mathrm{N}$ latitude, $80^{\circ} 27^{\prime} \mathrm{W}$ longitude). The site is located in the Ridge and Valley physiographic province and is dominated by red and white oaks (Quercus spp.), hickories (Carya spp.), and maples (Acer spp.). Site quality for the study area is $\mathrm{SI}_{50} 70$ for white oak (Q.alba), $700 \mathrm{~m}$ elevation, $120^{\circ}$ aspect, and $8-35^{\circ}$ slope.

We randomly assigned silvicultural treatments to adjacent 2 ha plots. Treatments included the removal of understory woody vegetation with herbicide, group selection, clearcut, leave-tree, two shelterwoods, and an unharvested control:

- Herbicide: Removed understory by thin-line individual stem (basal) application of Garlon $4{ }^{\mathbb{R}}$ herbicide (Triclopyr butoxyethyl ester). Herbicide treatment was intended to remove nondesirable understory woody vegetation to reduce competition to promote the growth of desirable species for timber products.

- Group selection: Removed a total of approximately 0.5 ha in three groups within the 2 ha treatment plot. The remaining trees are scheduled to be harvested on a 20 year cutting cycle.

- Clearcut: Removed all merchantable trees and stems down to $5 \mathrm{~cm}$ dbh from the treatment plot during a single harvest. Some mast, snag, and cull trees were left for wildlife, but total remaining trees did not exceed $6 \mathrm{ha}^{-1}$.

- Leave-tree: Single harvest in which between 3$4 \mathrm{~m}^{2}$ of basal area (BA) was retained per hectare. A maximum of 16 , evenly distributed, $>30 \mathrm{~cm}$ dbh trees were retained per hectare.

- Shelterwoods: One shelterwood treatment retained 4-7 $\mathrm{m}^{2}$ BA per hectare and one retained $12-15 \mathrm{~m}^{2}$ BA. The schedule for the removal of the residual overstory will depend on regeneration success of desired species.

- Control: Maintained as an unharvested control plot in which no silvicultural treatment was applied.

The long-term goal of this study was to monitor the effects of different silvicultural practices on terrestrial salamander richness and abundance over many years. Therefore, we selected sampling techniques that were repeatable and would not introduce bias to sampling in future years because of increased mortality of salamanders or destruction of habitat. We used night-time area-constrained $(2 \times 15 \mathrm{~m}$ transects) surveys and daytime sampling of artificial cover objects (Heyer et al., 1994). We allowed a $30 \mathrm{~m}$ buffer zone around transects and artificial cover objects on each treatment to reduce edge effects from adjacent treatments (Petranka et al., 1994).

We randomly selected and sampled one $2 \times 15 \mathrm{~m}$ transect per treatment per sample night. No transects were sampled more than once per season. Transects were evenly distributed on treatment plots. We began sampling approximately $1 \mathrm{~h}$ after sunset to ensure maximum darkness and continued until one area on every treatment had been sampled. To reduce observer bias, all seven treatment plots were sampled by the same searchers (two or three) on a given night. We captured only animals visible on the forest floor without disturbing cover objects.

To avoid potential bias associated with the activity of salamanders at certain times during the night (Holomuzki, 1980; Keen, 1984), we randomized the order in which we searched treatment plots. We sampled from April through June during or after rain when temperatures were above $7^{\circ} \mathrm{C}$ at night. In order to standardize for sampling conditions, we sampled only after enough rainfall so that the forest floor was wet under an intact canopy. We hand-captured all salamanders observed (Virginia Scientific Collection Permits \#SCP9454, 9527, 9632) and returned all animals after data collection to the exact site of capture within $24 \mathrm{~h}$.

Artificial coverboard sampling consisted of 50, $5 \times 30 \times 60 \mathrm{~cm}$ rough-cut poplar (Liriodendron tulipifera) boards placed in a grid pattern on each 2 ha treatment plot. Boards were placed on each site and allowed to weather for at least 1 month prior to sampling. We planned to check coverboards every 2 weeks during the postharvest sampling season, but we observed that the soil under boards dried out and boards were not used between rains on any treatments. Therefore, we sampled boards from April through July 1995 after enough rainfall to dampen the soil under the boards on treatments with an intact canopy (control and herbicide treatments). Intervals between sampling ranged from 3 to 18 days ( $n=10$ samples). We omitted three samples from data analysis because no salamanders were found under boards on any treatment plot.

We combined data from area-constrained searches within sample year for each treatment plot and tested 
for the treatment effect on relative abundance of all salamander species using Kruskal-Wallis one-way layout tests (Minitab, 1995). We tested for amongtreatment differences in the number of salamanders found under coverboards 1 year after harvest using a Kruskal-Wallis one-way layout (Minitab, 1995). We compared relative abundance estimated from night sampling with coverboards to identify trends.

We measured six microhabitat variables on each treatment plot in July and August 1995 after treatments were applied: soil moisture, soil temperature, leaf-litter biomass, leaf-litter moisture, leaf-litter ground coverage, and canopy coverage (see Harpole, 1996 for methods). We gravimetrically measured soil moisture and measured soil temperature at 2.5 and $10 \mathrm{~cm}$ depth. We gravimetrically measured leaf-litter moisture and drying rate on each treatment for three consecutive days after a $>2.5 \mathrm{~cm}$ rainfall. We categorically scored leaf-litter ground coverage and canopy coverage and calculated a mean score for each treatment.

\section{Results}

There was no significant difference in relative abundance of salamanders captured on area-con- strained searches among treatment plots before treatment (Kruskal-Wallis $H=1.64, \mathrm{df}=6, \quad p=0.949$ ). During April through October 1994, we captured 497 salamanders during eight sample nights (mean density of 0.30 salamanders $/ \mathrm{m}^{2}$ ). Mean number of salamanders observed on treatment plots ranged from 7.6 to 11.6 per transect. We captured red-backed (Plethodon cinereus), white-spotted slimy (P. cylindraceus), and northern dusky (Desmognathus fuscus) salamanders during area-constrained searches (Table 1). We identified an additional five species outside the sampling area but within the treatment plots (northern two-lined (Eurycea bislineata), northern red (Pseudotriton ruber), spring (Gyrinophilus porphyriticus), seal (Desmognathus monticola) salamander, red-spotted newt (Notophthalmus viridescens).

After treatment, red-backed salamanders accounted for $>95 \%$ of all salamanders captured and were the only species captured on all seven treatment plots. White-spotted slimy and northern dusky salamanders were captured during area-constrained searches (Table 1) and the other five species were occasionally observed on treatment plots.

There was no significant difference in the relative abundance of salamanders before and after harvest on

Table 1

Mean number of salamanders captured during area-constrained searches during April through June before harvest (1994) and after harvest $(1995-1997)$

\begin{tabular}{|c|c|c|c|c|c|c|c|c|}
\hline & Species & Control & Herbicide & $\begin{array}{l}\text { Group } \\
\text { selection }\end{array}$ & $\begin{array}{l}12-15 \mathrm{~m}^{2} \\
\text { shelterwood }\end{array}$ & $\begin{array}{l}4-7 \mathrm{~m}^{2} \\
\text { shelterwood }\end{array}$ & $\begin{array}{l}\text { Leave- } \\
\text { tree }\end{array}$ & Clearcut \\
\hline \multirow[t]{4}{*}{1994} & P. cinereus & 9.8 & 8.3 & 14.3 & 8.3 & 9.3 & 8.0 & 9.5 \\
\hline & P. cylindraceus & 0.0 & 0.5 & 0.0 & 0.5 & 0.3 & 0.3 & 0.3 \\
\hline & D. fuscus & 0.3 & 0.0 & 0.0 & 0.0 & 2.3 & 0.0 & 0.0 \\
\hline & All spp. (median) & $10.0(9.0)$ & $8.8(8.5)$ & $14.3(15.0)$ & $8.8(8.5)$ & $11.8(11.5)$ & $8.3(9.5)$ & $9.8(10.5)$ \\
\hline \multirow[t]{4}{*}{1995} & P. cinereus & 9.4 & 10.3 & 10.1 & 5.9 & 3.8 & 3.8 & 7.1 \\
\hline & P. cylindraceus & 0.8 & 0.6 & 0.5 & 0.4 & 0.0 & 0.0 & 0.4 \\
\hline & D. fuscus & 0.0 & 0.0 & 0.0 & 0.0 & 0.3 & 0.0 & 0.0 \\
\hline & All spp. (median) & $9.8(9.5)$ & $10.9(9.5)$ & $10.5(10.0)$ & $6.1(4.5)$ & $3.9(3.5)$ & $3.8(3.5)$ & $7.3(7.0)$ \\
\hline \multirow[t]{4}{*}{1996} & $P$. cinereus & 7.2 & 10.3 & 3.7 & 2.2 & 1.3 & 1.1 & 2.0 \\
\hline & P. cylindraceus & 0.1 & 0.8 & 0.0 & 0.0 & 0.0 & 0.0 & 0.0 \\
\hline & D. fuscus & 0.0 & 0.0 & 0.0 & 0.0 & 0.3 & 0.0 & 0.0 \\
\hline & All spp. (median) & $7.3(7.0)$ & $11.1(11.0)$ & $3.7(4.0)$ & $2.2(2.0)$ & $1.8(1.0)$ & $1.1(1.0)$ & $2.0(2.0)$ \\
\hline \multirow[t]{4}{*}{1997} & $P$. cinereus & 6.4 & 10.6 & 2.3 & 2.0 & 0.6 & 0.5 & 0.9 \\
\hline & P. cylindraceus & 1.0 & 0.4 & 0.0 & 0.0 & 0.0 & 0.0 & 0.0 \\
\hline & D. fuscus & 0.3 & 0.0 & 0.0 & 0.0 & 0.3 & 0.0 & 0.0 \\
\hline & All spp. (median) & $7.8(8.0)$ & $11.0(10.0)$ & $2.3(1.0)$ & $2.0(1.5)$ & $0.9(1.0)$ & $0.5(0.0)$ & $0.9(1.0)$ \\
\hline$p$-value & & 0.788 & 0.862 & 0.005 & 0.007 & 0.015 & 0.001 & 0.001 \\
\hline
\end{tabular}




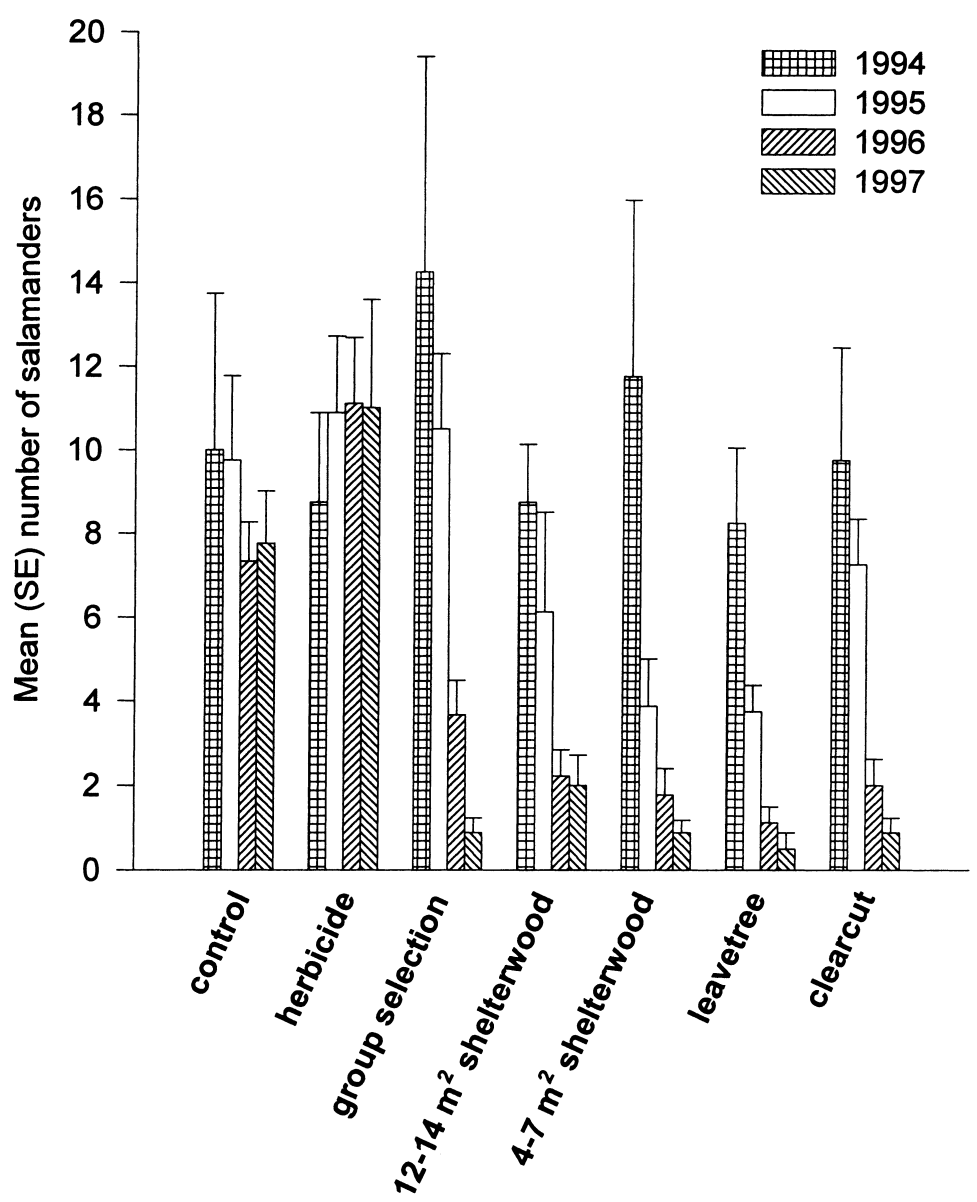

Fig. 1. Mean (SE) number of salamanders captured per area-constrained search before harvest (1994) and after harvest (1995-1997).

the control $(p=0.788)$ and herbicide $(p=0.862)$ treatments (Table 1). There was a significant decrease in the number of salamanders captured after treatment on the group selection $(p=0.005), 12-15 \mathrm{~m}^{2}$ BA shelterwood $(p=0.007), 4-7 \mathrm{~m}^{2}$ BA shelterwood $(p=0.015)$, leave-tree $(p=0.001)$, and clearcut $(p=0.001)$ plots (Table 1)(Fig. 1).

We found the most salamanders under coverboards (mean $\pm \mathrm{SE}$ ) on the herbicide $(7.4 \pm 2.0)$ and control (5.0 \pm 1.6$)$ treatments, followed by the group selection (3.0 \pm 1.2$), \quad 12-15 \mathrm{~m}^{2}$ BA shelterwood $(1.4 \pm 0.5)$, clearcut $(1.1 \pm 0.5), \quad 4-7 \mathrm{~m}^{2} \quad$ BA shelterwood $(1.0 \pm 0.5)$, and leave-tree $(0.8 \pm 0.4)$. The highest coverboard use on any sample date occurred on the herbicide understory treatment and consisted of 14 boards, each occupied by a single red-backed salamander, out of 50 coverboards (28\%). There was a significant difference in among-treatment salamander use of coverboards $(p=0.005, H=18.74$, $\mathrm{df}=6$ ).

Soil temperature at 2.5 and $10 \mathrm{~cm}$ was highest on treatments with the most canopy removed (clearcut, leave-tree, 4-7 $\mathrm{m}^{2}$ BA shelterwood, and group selection) (Table 2). Percent soil moisture was highest on the clearcut and group selection (Table 2). Means of leaf-litter biomass did not differ greatly among treatments, but variability was higher on sites with the most trees removed (clearcut, leave-tree, and 4-7 $\mathrm{m}^{2}$ BA shelterwood) (Table 2). Percent leaf-litter moisture was the highest on each of the three consecutive days after rain on the control and herbicide plots (Fig. 2). The clearcut, leave-tree, and 4-7 $\mathrm{m}^{2}$ BA shelterwood 
Table 2

Mean (SE) percent soil moisture, soil temperature $\left({ }^{\circ} \mathrm{C}\right)$, leaf-litter biomass $\left(\mathrm{g} / \mathrm{m}^{2}\right)$, canopy and leaf-litter coverage (mean relative score based on 0-5 ranking) in 1995 (1 year postharvest)

\begin{tabular}{|c|c|c|c|c|c|c|c|}
\hline Variable & Control & Herbicide & Group selection & $12-14 \mathrm{~m}^{2}$ shelter & 4-7 $\mathrm{m}^{2}$ shelter & Leave-tree & Clearcut \\
\hline$\%$ soil moisture & $11.8(0.6)$ & $14.2(0.5)$ & $16.4(0.8)$ & $11.6(0.4)$ & $15.3(1.3)$ & $13.8(1.1)$ & $16.7(0.7)$ \\
\hline \multicolumn{8}{|l|}{ Soil temperature } \\
\hline $2.5 \mathrm{~cm}$ & $18.6(0.3)$ & $17.5(0.2)$ & $20.7(0.4)$ & $19.5(0.4)$ & $21.3(0.3)$ & $22.2(0.4)$ & $22.1(0.3)$ \\
\hline $10 \mathrm{~cm}$ & $17.1(0.2)$ & $16.2(0.1)$ & $17.8(0.4)$ & $17.6(0.2)$ & $19.0(0.3)$ & $19.1(0.5)$ & $18.6(0.3)$ \\
\hline Leaf-litter biomass & $40.4(2.4)$ & $46.0(2.8)$ & $45.2(3.2)$ & $49.6(2.8)$ & $62.0(4.0)$ & $49.6(4.0)$ & $53.2(4.8)$ \\
\hline Canopy coverage & 4.5 & 4.4 & 2.1 & 2.7 & 1.6 & 1.1 & 0.46 \\
\hline Litter coverage & 4.7 & 4.8 & 3.8 & 4.1 & 3.2 & 3.2 & 2.9 \\
\hline
\end{tabular}

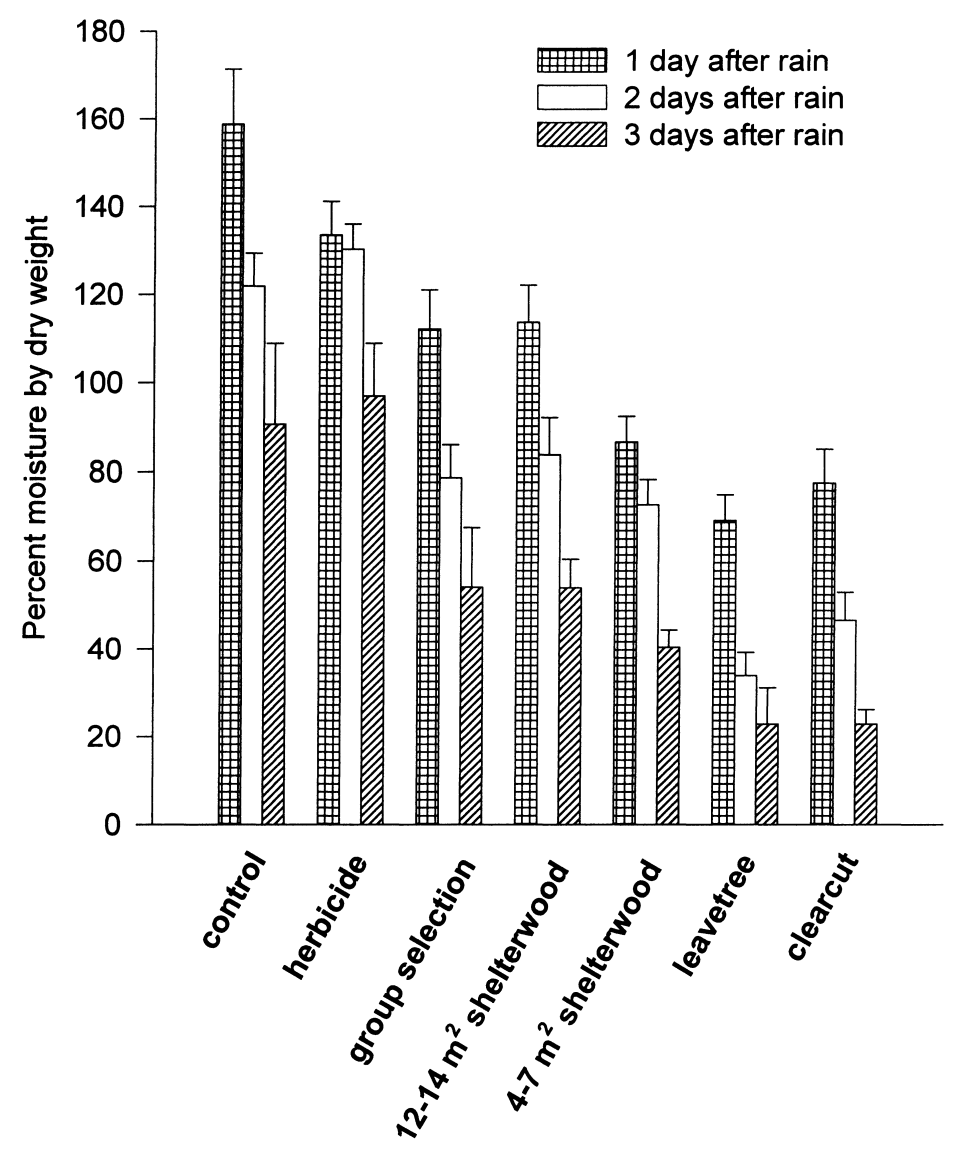

Fig. 2. Percent moisture of leaf litter collected on 3 consecutive days after rain ( $n=10$ per treatment per day).

had the lowest percent litter moisture. Canopy and litter coverage was greatest in the control and herbicide plots and corresponded directly with intensity of treatment (Table 2).

\section{Discussion}

Relative abundance based on area-constrained searches decreased on the five treatment plots in which 
trees were harvested and remained stable on the control and herbicide treatment. While understory vegetation was reduced after the herbicide treatment, the canopy remained intact and the microhabitat conditions appeared similar to the control plot (Harpole, 1996). Relative to other treatments, the control and herbicide plots had cooler soil temperatures, lower variability in leaf-litter biomass, higher retention of moisture by leaf litter, higher leaf-litter ground coverage, and greater canopy coverage.

Results from artificial coverboards follow the same trend as results from night-time area-constrained sampling. More salamanders were found under coverboards on control and herbicide plots than plots with some canopy removed. Boards dried out within a week after rainfall and were not occupied until sufficient rainfall to re-wet them. With the exception of a single juvenile white-spotted slimy salamander, only red-backed salamanders were found under artificial coverboards. We captured an average of 8.4 redbacked salamanders per 50 boards on unharvested treatment plots during optimal (cool and wet) sampling dates and no salamanders under boards during warm or dry periods. The maximum number of salamanders captured during any sample date was 14 . Coverboard use on harvested plots never exceeded eight per 50 boards, averaged only 1.5 per 50 on the group selection plot, and averaged less than 1.5 salamanders per 50 boards on all other treatments. Following our sampling schedule (checking boards 2-3 days after each rainfall), we only found salamanders under boards on all treatment plots on three of the 10 sample dates. On sites with greater rainfall, northern aspect, higher elevation, or lower temperatures the boards probably would have been more effective.

Red-backed salamanders accounted for $>92 \%$ of the total number of salamanders captured before and after harvest and were found on all treatment plots before and after harvest. White-spotted slimy salamanders were found on all plots before harvest but were absent 3 years after harvest on all treatments in which the canopy was removed with the exception of two juveniles (27.1 and 45.0 $\mathrm{mm} \mathrm{SVL}$ ) found on the group selection treatment in 1997. This may suggest differences in microclimate tolerances between larger plethodontids such as white-spotted slimy salamanders and smaller plethodontids such as red-backed salamanders. We captured northern dusky salaman- ders on four of the seven treatment plots but they accounted for $<3 \%$ of total captures on any plot except for the 4-7 $\mathrm{m}^{2} \mathrm{BA}$ shelterwood (12\%). Deleting northern dusky salamanders from analysis did not affect the results. Mean number of salamanders caught per sample night on the 4-7 $\mathrm{m}^{2}$ BA shelterwood during preharvest, 1-3 years postharvest, excluding northern dusky was 17.0, 4.4, 1.3, and 0.6, respectively. We found too few $(<10)$ individuals of the other species during preharvest and postharvest sampling to identify any trends in the presence or absence as a result of treatment effect.

Red-backed salamanders, like other ectotherms, show a direct correlation between basal metabolic rate and temperature. In addition, they are lungless and respire primarily through their moist skin. Surface activity is therefore restricted to cool, moist periods. Because their caloric requirements increase and digestive efficiencies decrease with increasing temperatures (Bobka et al., 1981) and they experience fewer foraging opportunities when their habitat becomes dry (Jaeger, 1980), terrestrial salamanders may have difficulty maintaining a positive energy balance on sites that have been harvested. Leaf-litter moisture was lowest on each of the three consecutive days after rain on the treatment plots with the most canopy removed (4-7 $\mathrm{m}^{2}$ BA shelterwood, leave-tree, and clearcut) (Fig. 2). On sites with more canopy cover, salamanders will have more foraging opportunities because the leaf-litter retains more moisture for several days after rain.

The effects of the silvicultural treatments may not be fully manifested on salamander populations for several years. Most plethodontid salamanders are long-lived (up to 10 years) and reproduce every 2 years (Duellman and Trueb, 1986; Hairston, 1987). An accurate assessment of the effects of silvicultural treatments requires sampling populations over several reproductive seasons.

Pough et al. (1987) found no significant difference in the number of red-backed salamanders in a 60-yearold second growth forest and an adjacent old-growth forest and determined that the depth of leaf-litter was the best predictor of above-ground salamander abundance. Likens et al. (1978) found that about 65 years are required to rebuild organic matter in the forest floor to pre-clearcut harvest levels. If the forest floor recovery time is shorter in harvests that remove less of 
the canopy (e.g., shelterwood, group selection, and leave-tree harvests), salamander populations may be able to persist or recover faster under these regeneration methods relative to clearcuts. However, if even slight canopy disturbance has strong negative effects on salamander populations, then forests managed by clearcutting may maintain larger populations of salamanders, because a smaller area is disturbed in any given year to obtain the same volume of wood.

Removing only a portion of the forest canopy creates microclimate conditions that are cooler and retain more surface moisture than clearcuts (Johnson et al., 1985; Harpole, 1996). Treatments that remove less canopy might be habitable by salamanders sooner after harvest than clearcuts because of the cumulative effect of regenerating young trees and the initial retention of part of the canopy. However, if partial harvests occur on a cutting cycle that is shorter than the time it takes salamanders to repopulate the harvested site, harvesting the remaining trees may again reduce populations and increase the time required for salamander populations to return to preharvest levels.

\section{Conclusions}

The primary goal of this experiment was to compare the effects over time of seven silvicultural alternatives on terrestrial salamanders. We are currently sampling this site and six additional sites that were harvested in 1996 or are scheduled for harvesting during 19971998. Long-term data on salamander populations are relatively rare and are essential for effective management (Heyer et al., 1994). In addition, few studies have compared the effects of different forest management practices on salamander populations and few studies have both pre- and postharvest data from the same location. Our results indicate that terrestrial salamander populations significantly decline within 3 years after even partial removal of the forest canopy on lowelevation south-facing slopes. Long-term monitoring of salamander populations is necessary to better understand the effects of silviculture on terrestrial salamanders.

\section{Acknowledgements}

David W. Smith, Shepard M. Zedaker, and James E. Johnson were instrumental in the design and establish- ment of silvicultural treatments. We acknowledge the USDA Forest Service Southeast Experiment Station for start-up funding and the USDA National Research Initiative Competitive Grants Program for continuing support. We thank Don Mackler and numerous technicians and volunteers for help in salamander sampling. David K. Wright, Brian P. Oswald, and two anonymous reviewers provided helpful comments on this manuscript.

\section{References}

Ash, A.N., 1988. Disappearance of salamanders from clearcut plots. J. Elisha Mitchell Sci. Soc. 104(3), 116-122.

Bennett, S.H., Gibbons, J.W., Glanville, J., 1980. Terrestrial activity, abundance, and diversity of amphibians in differently managed forest types. Am. Midl. Nat. 103(2), 412-416.

Bobka, M.S., Jaeger, R.G., McNaught, D.C., 1981. Temperature dependent assimilation efficiencies of two species of terrestrial salamanders. Copeia 1981(2), 79-83.

Brodie Jr., E.D., Howard, R.R., 1973. Experimental study of Batesian mimicry in the salamanders Plethodon jordani and Desmognathus ochrophaeus. Am. Midl. Nat. 90, 38-46.

Brodie, E.D., Jr., Nowak, R.T., Harvey, W.R., 1979. The effects of anitpredator secretions and behavior of selected salamanders against shrews. Copeia, 270-274.

Burton, T.H., Likens, G.E., 1975. Salamander populations and biomass in the Hubbard Brook Experimental Forest, New Hampshire. Ecology 56(5), 1068-1080.

Duellman, W.E., Trueb, L., 1986. Biology of Amphibians. McGraw-Hill, New York, p. 670.

Fraser, D.F., 1976. Empirical analysis of the hypothesis of food competition in salamanders of the genus Plethodon. Ecology 57(3), 459-471.

Hairston, N.G., 1987. Community Ecology and Salamander Guilds. Cambridge University Press, Cambridge, UK, p. 230.

Harpole, D.N., 1996. Terrestrial salamanders in southern Appalachian hardwood forests: relative abundance, nutritional condition, and response to silvicultural practices. MS thesis, Virginia Tech, Blacksburg, VA, p. 93.

Heyer, W.R., Donnelly, M.A., McDiarmid, R.W., Hayek, L.C., Foster, M.S., 1994. Measuring and Monitoring Biological Diversity: Standard Methods for amphibians. Smithsonian Institution Press, Washington and London, p. 364.

Holomuzki, J.R., 1980. Synchronous foraging and dietary overlap of three species of plethodontid salamanders. Herpetologica 36(2), 109-115.

Jaeger, R.G., 1980. Fluctuations in prey availability and food limitation for a terrestrial salamander. Oecologica 44, 335-341.

Johnson, J.E., Smith, D.W., Burger, J.A., 1985. Effects on the forest floor of whole-tree harvesting in an Appalachian oak forest. Am. Midl. Nat. 114(1), 51-61.

Keen, W.H., 1984. Influence of moisture on the activity of a plethodontid salamander. Copeia No. 3, 684-688. 
Likens, G.E., Bormann, F.H., Pierce, R.S., Reiners, W.A., 1978. Recovery of a deforested ecosystem. Science 199, 492-496.

Minitab Release 10 Xtra Reference Manual. 1995. Minitab, State College, PA.

Petranka, J.W., Eldridge, M.E., Haley, K.E., 1993. Effects of timber harvesting on southern Appalachian salamanders. Cons. Biol. 7(2), 363-370.

Petranka, J.W., Brannon, M.P., Hopey, M.E., Smith, C.K., 1994.
Effects of timber harvesting on low elevation populations of southern Appalachian salamanders. For. Ecol. Manage. 67, 135-147.

Pough, F.H., 1980. The advantages of ectothermy for tetrapods. Am. Nat. 115(1), 92-112.

Pough, F.H., Smith, E.M., Rhodes, D.H., Collazo, A., 1987. The abundance of salamanders in forest stands with different histories of disturbance. For. Ecol. Manage. 20, 1-9. 